\title{
Molecular Approaches to the Treatment, Prophylaxis, and Diagnosis of Alzheimer's Disease: Clinical Molecular and Genetic Studies on Alzheimer's Disease
}

\author{
Mikio Shoji ${ }^{1, *}$ \\ ${ }^{1}$ Department of Neurology, Hirosaki University Graduate School of Medicine, \\ 5 Zaifucho, Hirosaki, Aomori 036-8216, Japan
}

Received November 6, 2011; Accepted January 6, 2012

\begin{abstract}
Recent advances in clinical molecular and genetic studies on Alzheimer's disease (AD) are summarized here. Cerebrospinal fluid (CSF) A $\beta 42$ and tau are the most sensitive biomarkers for the diagnosis of $\mathrm{AD}$ and prediction of its onset following mild cognitive impairment (MCI). Based on this progress, new diagnostic criteria for $\mathrm{AD}$ dementia, MCI due to $\mathrm{AD}$, and preclinical AD were proposed by the National Institute of Aging (NIA) and Alzheimer's Association (AA) in April 2011. In these new criteria, progress in CSF biomarker and amyloid imaging studies over the past 10 years has added to critical information. The marked contributions of basic and clinical studies have established clinical evidence supporting these markers. Based on this progress, essential curative therapy for AD is urgently expected.
\end{abstract}

Keywords: Alzheimer's disease, mild cognitive impairment, amyloid $\beta(\mathrm{A} \beta)$, tau, biomarker

\section{Introduction}

The number of patients with dementia has been increasing exponentially with the aging of societies in advanced and Asian countries. About 24,300,000 people are considered to have dementia worldwide. More than 2,500,000 people suffer from dementia in Japan. A half of the cases of dementia is caused by Alzheimer's disease (AD). Over the last 10 years, AD research has clarified that the pathological process of $\mathrm{AD}$ is initiated by $\mathrm{A} \beta$ amyloidosis with secondary tauopathy, highlighting a strategy for developing drugs that may improve or cure AD. Mild cognitive impairment (MCI) as a prodromal stage of $\mathrm{AD}$, and the pathogenesis of Dementia with Lewy bodies (DLB) and Frontotemporal lobar degeneration (FTLD) as a non-AD type dementia have also been elucidated. Currently, a consortium study by the Alzheimer Disease Neuroimaging Initiative (ADNI) is being performed to establish global standardization regarding neuropsychiatric tests, cerebrospinal fluid (CSF) biomarkers, and neuroimaging including magnetic resonance

*Corresponding author. mshoji@cc.hirosaki-u.ac.jp Published online in J-STAGE on March 2, 2012 (in advance) doi: 10.1254/jphs.11R13FM imaging (MRI), fluorodeoxy glucose (FDG) - positron emission tomography (PET), and amyloid PET to predict the progression from $\mathrm{MCI}$ to $\mathrm{AD}$ and to promote studies of basic therapy for $\mathrm{AD}(1)$.

In each advanced country, clinical guidelines for the diagnosis and treatment of dementia have been established. Studies to establish clinical evidence for symptomatic drugs, such as donepezil, rivastigmine, and memantine; cognitive rehabilitation; and care for $\mathrm{AD}$ are now ongoing. Based on this progress, the revision of diagnostic criteria for $\mathrm{AD}$ by the National Institute of Neurological Disorders and Stroke / Alzheimer's Disease and Related Disorders Association (NINDS/ADRD) was proposed by National Institute of Aging (NIA) and Alzheimer's Association (AA) work groups after an interval of 27 years $(2,3)$. Approximately 10 years have passed since the usage of donepezil, start of public nursing care insurance to care for patients and their families, and legislative preparations in Japan. Clinical guidelines for dementia treatment were reviewed by the Japanese Neurological Society and 5 related societies (4). Now are we involved in the new step of clinical molecular and genetic studies on $\mathrm{AD}$. 


\section{Advances in studies on pathogenesis of AD}

In 1999, presenilin was shown to be the main component of $\gamma$-secretase by Selkoe (5), and the possibility of medical treatment using amyloid $\beta(\mathrm{A} \beta)$ vaccine or antibodies to $\mathrm{A} \beta$ was reported by Schenk in the same year (6). After these epochal findings, an enormous effort to elucidate the presenilin- $\gamma$-secretase complex, $\mathrm{A} \beta$ generation/metabolism, and its regulation system has been made to identify radical therapy for $\mathrm{A} \beta$ amyloidosis (Fig. $1)$. The first large-scale multicenter follow-up study of the decreased level $\mathrm{A} \beta 42$ and increased total tau level in CSF as diagnostic markers of AD was reported in 1998 (7). The first report on MCI by Petersen was published in 1999 (8), and the first report on Pittsburgh Compound B (PIB) amyloid PET by Klunk was published in 2004 (9). The usage of donepezil was initiated in 1999, and the nursing-care insurance system was started in 2000, leading to marked changes in the treatment and care systems for dementia in Japan.

In studies of AD-related genes, almost all familial gene variation in AD concentrates on APP, PSEN1, and PSEN2, and APOE genetic polymorphism is the strongest risk factor for AD. Associated genetic studies on $\mathrm{AD}$ have also revealed the presence of many associated genes such as DMP, SORL1, CTNNA3, PCDH11X, CLU, CR1, PICALM, BIN1, CNTN5, MS4A4/MS4A6E, EPHA1, CD33, or CD2AP, involving large-scale genome-wide studies $(10,11)$. In contrast, large scale prospective studies to evaluate and standardize the natural course of the pathological and clinical development of $\mathrm{AD}$ have also been performed, such as the Braak and Braak stage classification of AD pathology (12), Nun study (13), and Hisayamamachi study (14). For evaluation of the cognitive function or efficiency of drug trials, global standardizations of neuropsychiatry tests, such as Mini-mental state examination (MMSE), clinical dementia rating (CDR), Wechsler memory scale-revised

\section{Advances in Alzheimer's research over the last 10 years All familial $A D$ gene mutations increase $A B 42$ and $A B$ oligomer}

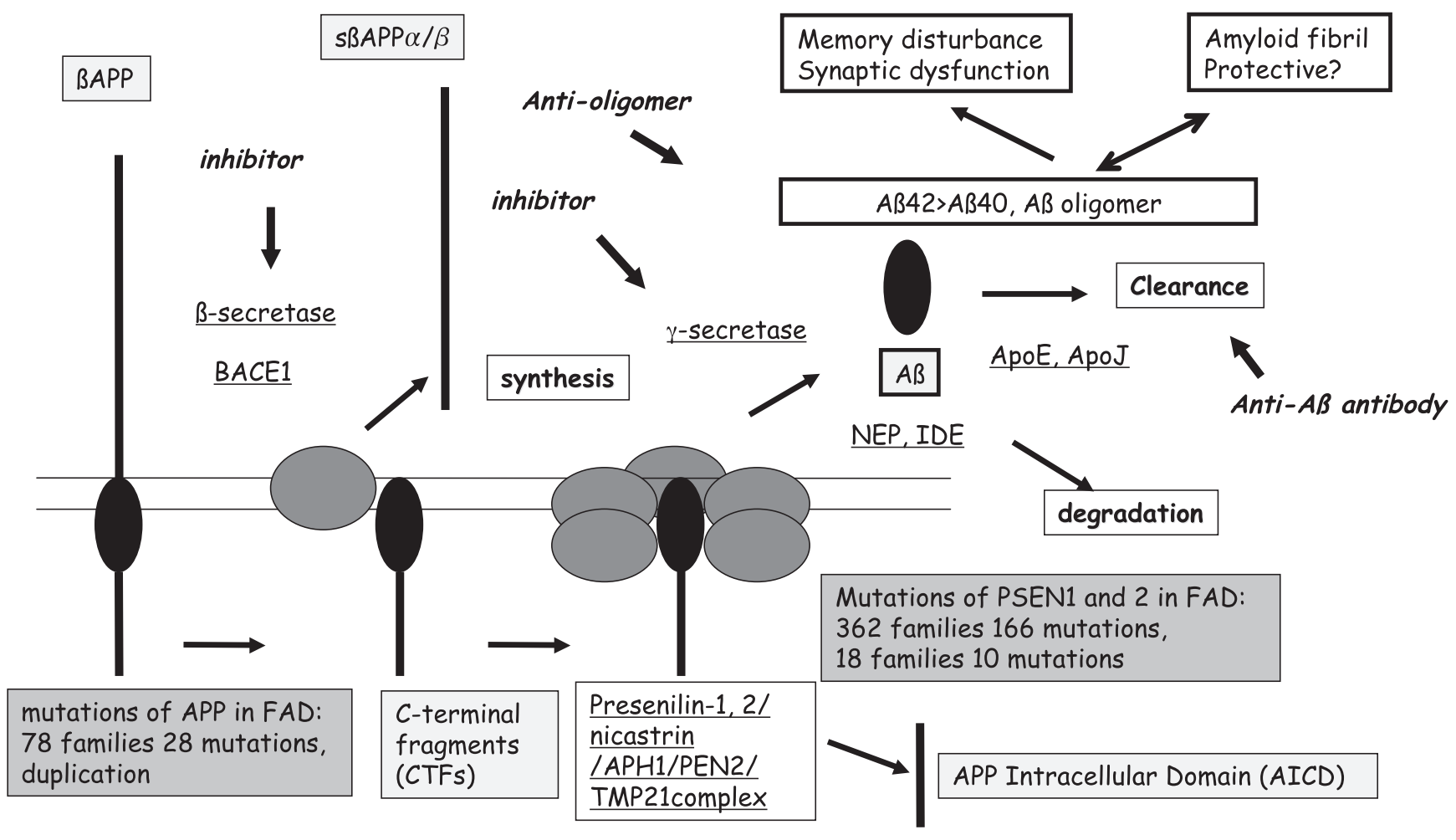

Fig. 1. Summary of advances in Alzheimer's research over the last 10 years. The gain of function role of these responsible gene mutations finally causes an increased synthesis of $\mathrm{A} \beta 42$ or $\mathrm{A} \beta$ oligomers. Amyloid $\beta$ protein precursor ( $\beta \mathrm{APP})$ is cut by $\beta$-secretase (BACE1) to produce secretory forms of $\beta \mathrm{APP} \alpha / \beta$ and CTF (C-terminal fragments of $\beta \mathrm{APP}$ ) and then cut by $\gamma$-secretase (presenilin-1, 2/nicastrin/APH1/PEN2/TMP21 complex) to generate A $\beta$ and AICD ( $\beta$ APP intracellular domain). Based on these findings, possible anti-A $\beta$ amyloidosis therapies including $\beta$-, $\gamma$-secretase inhibitors and anti-A $\beta$ antibodies and anti-A $\beta$ oligomer antibodies have been studied. 
(WMS-R), and Wechsler adult intelligence scale-III (WAIS-III), and Alzheimer's Disease Assessment Scale cognitive part (ADAS-Cog) have also been carried out (1). In neuroimaging diagnosis, 3 tesla MRI imaging, high-resolution single photon emission computed tomography (SPECT), and FDG-PET using statistical image processing such as three-dimensional stereotactic surface projections (3D-SSP) became clinically available, and the validity of these neuroimaging approaches was established (4). The rapid development and spread of amyloid PET images have provided a qualitative aspect to the diagnosis and discrimination of $\mathrm{AD}$. Thus, many studies on the neuropsychiatric characteristics, risk factors, neuroimaging, biomarkers, natural course, and progression of MCI have been conducted over the last 10 years and the findings have led to the current ADNI study (1).

Immunotherapy for $\mathrm{A} \beta$ amyloidosis has received the attention of the entire world, leading to many interesting findings; however, markedly effective results have yet to be reported. Long-term observation results from a 5 -year follow-up study involving a phase I trial of the $\mathrm{A} \beta 42$ vaccine AN1792 were reported in 2008, and the side effects, encephalitis, and failure to improve the cognitive function though brain amyloid accumulation disappeared. However, effective results employing the Disability Assessment for Dementia scale and Dependence Scale for antibody positive participant groups were reported in a follow-up survey lasting 4.6 years involving a phase II trial in 2009 (15). Improvement of the brain amyloid burden and neurite abnormality in the hippocampus and decreased phosphorylated tau-positive nerve cells were also shown, suggesting that $\mathrm{A} \beta$ antibody therapy may be effective for a tauopathy-associated pathology (16). At least 7 clinical trials of different anti-A $\beta$ antibodies are now ongoing in phase II to III stages. As for semagacestat, a $\gamma$-secretase inhibitor, a clinical trial was canceled in phase II due to there being no improvement of cognitive dysfunction and disability levels of Activities of Daily Living (ADL) and the development of skin cancer. Since semagacestat was seen as a promising drug for $\mathrm{A} \beta$ amyloidosis among other $\gamma$-secretase inhibitors, cancellation of the clinical trial was very disappointing. It seems that the development of a radical therapeutic drug will take more time. Candidates for new disease-modifying drugs that reduce $\mathrm{A} \beta$ amyloidosis and improve the cognitive function were reported in Japan, such as apomorphine (17) or anti-A $\beta$ oligomer antibody (18), although they remain at animal experimental stages.

\section{CSF A $\beta 40, A \beta 42$, tau, and phosphorylated tau}

$\mathrm{A} \beta$ levels in CSF are controlled by orexin, suggesting the presence of a daily change in the CSF A $\beta$ level (19).
$\mathrm{A} \beta$ is produced mainly in the nerve cells of the brain, and it is secreted about $12 \mathrm{~h}$ later into the CSF, then excreted through the blood-brain barrier 24-h later into blood (A $\beta$ clearance), and finally degraded in the reticuloendothelial system (20). In AD brains, $A \beta 42$ forms insoluble amyloids and accumulates as insoluble amyloid fibrils in the brain. The reason why A $\beta 42$ levels are decreased in the $\mathrm{CSF}$ of $\mathrm{AD}$ patients is considered to be the deterioration of physiologic $\mathrm{A} \beta$ clearance into the CSF in $\mathrm{AD}$ brains (21). CSF total tau levels increase slightly with aging. However, CSF tau levels show a 3-fold greater increase in $\mathrm{AD}$ patients than in normal controls. The CSF tau level is related to the degeneration of axons and neurons and to severe destructive disease of the nervous system. Several diseases show slightly increased tau levels such as vascular dementia (VaD), multiple sclerosis, AIDS dementia, head injury, and tauopathy (22).

\section{Clinical evidence, sensitivity, and specificity}

In the first large-scale collaborative multicenter study of CSF A $\beta 40, \mathrm{~A} \beta 42$, and total tau, a total of 236 subjects were followed in Japan and showed a diagnostic sensitivity of $71 \%-91 \%$ and specificity of $83 \%$ in AD in 1998 (7). A European and American large-scale multicenter study showed a diagnostic sensitivity of $85 \%$ and specificity of $86 \%$ (23). A large-scale multicenter Japanese study of CSF total tau alone in 1,031 subjects reported a sensitivity of $59 \%$ and specificity of $90 \%$ for a diagnosis of AD (22). Practical guidelines for dementia proposed by the American Academy of Neurology in 2001 showed a diagnostic sensitivity of $78 \%-92 \%$ and specificity of $81 \%-83 \%(24)$.

In the examination of CSF phosphorylated tau, the first study of p-tau199 was reported as a large-scale multicenter collaborative study by a Japanese group and showed a diagnostic sensitivity of $85 \%$ and specificity of $85 \%$ in a comparison between $\mathrm{AD}$ and non-AD disease controls (25). Assay systems using different epitopes of phosphorylated tau (p-tau231, p-tau181, and p-tau199) have been internationally standardized. A systematic review of CSF biomarkers for AD in 2001 analyzed 41 studies of CSF total tau, 15 studies of $A \beta 42$, and 11 studies of p-tau; 5 studies on the diagnosis of early AD; and 9 studies of MCI; it showed that the respective specificities and sensitivities were $90 \%$ and $81 \%$ for CSF total tau, $90 \%$ and $86 \%$ for CSF $\mathrm{A} \beta 42,92 \%$ and $80 \%$ for CSF phosphorylated tau, and $83 \%-100 \%$ and $85 \%-95 \%$ in the combination assay with $\mathrm{CSF} \mathrm{A} \beta 42$ and total tau (26). 


\section{CSF biomarkers for prediction of the onset of $A D$ from MCI}

A study following $52 \mathrm{MCI}$ subjects for 8.4 months found that $29 \mathrm{MCI}$ subjects developed $\mathrm{AD}$ and the specificity of the CSF A $\beta 42$ assay was $90 \%$ (27). A follow-up study of 273 subjects for 2 years showed that $38 \%$ of MCI already showed the alteration of at least $2 \mathrm{CSF}$ biomarkers including $\mathrm{A} \beta 42$, total tau, and $\mathrm{p}$-tau 181 at the time of study initiation. Ten of 11 MCI patients who progressed to $\mathrm{AD}$ showed the alteration of at least $2 \mathrm{CSF}$ biomarkers, and all 11 converters showed high p-tau181 levels in CSF. Conversely, 29 (88\%) of the 33 stable MCI subjects did not show any alteration of CSF biomarkers (28). The longest prospective study ( $4-6$ years) followed $137 \mathrm{MCI}$ and 39 normal subjects and showed that the onset of $\mathrm{AD}$ was predicted with a sensitivity of $95 \%$ and specificity of $83 \%$ using CSF A $\beta 42$ and total tau assays. The addition of the p-tau181 assay further improved sensitivity and specificity to $95 \%$ and $97 \%$, respectively (29). In comparison studies between CSF biomarkers and amyloid imaging by PIB-PET, CSF A $\beta 42$ levels were related to brain amyloid deposits in patients with or without dementia (30). In the United States-ADNI, 819 healthy subjects (229 normal, 398 MCI, 192 mild AD) were prospectively studied. The results one year later showed that the mean AD conversion/ year was $16.5 \%$. Among all CSF biomarkers, $\mathrm{A} \beta 42$ at the initial evaluation was the most reliable marker predicting conversion from $\mathrm{MCI}$ to $\mathrm{AD}$ and the progression of cognitive impairment. Using the CSF total tau/A $\beta 42$ ratio, 33 converters $(89 \%)$ were predicted before onset among 37 subjects who progressed from MCI to AD within one year (31).

\section{Revised diagnostic criteria for AD}

The NINCDS-ADRDA as the standard clinical criteria for $\mathrm{AD}$ discriminates probable $\mathrm{AD}$ with a sensitivity of $81 \%$ and specificity of $70 \%$. Based on progress in research during these 27 years, NIA and AA proposed new diagnostic criteria of AD in April 2011 (2). Conventional probable AD was called probable AD Dementia. The criteria were divided into core clinical criteria based on clinical symptoms and research criteria including CSF biomarkers, PIB amyloid PET, FDG-PET, MRI, and genetic tests. $\mathrm{MCI}$ due to $\mathrm{AD}$ is proposed as a possible converter to $\mathrm{AD}$ dementia with a decline in specific neuropsychiatric tests $(1-1.5 \mathrm{SD})(3)$. A large prospective consortium study of MCI due to AD from preclinical $\mathrm{AD}$ is going to be performed in ADNI-II following ADNI, and further fruitful results are expected over the next 5 years.

\section{Conclusion: $\mathbf{A} \boldsymbol{\beta}$ cascade hypothesis or $\mathbf{A} \boldsymbol{\beta} /$ tau cas- cade hypothesis?}

Here, I summarized the advances in the clinical, molecular, and genetic studies over the last 10 years and suggested future prospects. However, when will we reach the stage of radical therapy and prevention of $\mathrm{AD}$ as the final aim? Studies on AD continuously showed essential approaches and methods to clarify the pathogenesis and how to evaluate clinical issues and develop radical therapy as crucial in the field of research on neurodegenerative disorders over the last 10 years. The development of many candidate drugs for radical therapy such as $\mathrm{A} \beta$ vaccines or $\gamma$-secretase inhibitors is now hampered by the lack of phase III clinical trials. A large degree of skepticism exists regarding the $\mathrm{A} \beta$ amyloid cascade hypothesis because aggravation of dementia is not stopped even if the $\mathrm{A} \beta$ vaccine removes $\mathrm{A} \beta$ amyloid deposits. Revisions of the $\mathrm{A} \beta$ cascade hypothesis have been announced by Hardy and Hymann, who initially proposed this hypothesis $(32,33)$. $\mathrm{A} \beta$ amyloidosis, tauopathy, and neuronal cell death were cardinal clues to clarify all pathological processes from the early to late stages of $\mathrm{AD}$, and researchers changed the focus repeatedly depending on the trend of the times. It should be considered that many issues still remain to be clarified from $\mathrm{A} \beta$ amyloidosis to tauopathy leading to nerve cell losses. I support this thought based on the findings of associated genes detected by global genome-wide studies and the results using animal models that represent $\mathrm{A} \beta$ amyloidosis and tauopathy. It is necessary to elucidate all associated molecules in every step of the pathological cascades of $\mathrm{AD}$ and refine the target molecules to develop a therapy to cure $\mathrm{AD}$.

\section{References}

1 Petersen RC, Aisen PS, Beckett LA, Donohue MC, Gamst AC, Harvey DJ, et al. Alzheimer's disease neuroimaging initiative (ADNI): clinical characterization. Neurology. 2010;74:201-209.

2 McKhann GM, Knopman DS, Chertkow H, Hyman BT, Jack CR Jr, Kawas CH, et al. The diagnosis of dementia due to Alzheimer's disease: recommendations from the National Institute on AgingAlzheimer's Association workgroups on diagnostic guidelines for Alzheimer's disease. Alzheimers Dement. 2011;7:263-269.

3 Albert MS, DeKosky ST, Dickson D, Dubois B, Feldman HH, Fox NC, et al. The diagnosis of mild cognitive impairment due to Alzheimer's disease: recommendations from the National Institute on Aging-Alzheimer's Association workgroups on diagnostic guidelines for Alzheimer's disease. Alzheimers Dement. 2011; 7:270-279.

4 Japanese Collabarating Working Group for Therapy for Dementia. Gudeline for therapy of dementia 2010. Tokyo: Igakushoin; 2010.

5 Wolfe MS, Xia W, Ostaszewski BL, Diehl TS, Kimberly WT, 
Selkoe DJ. Two transmembrane aspartates in presenilin-1 required for presenilin endoproteolysis and gamma-secretase activity. Nature. 1999;398:513-517.

6 Schenk D, Barbour R, Dunn W, Gordon G, Grajeda H, Guido T, et al. Immunization with amyloid-beta attenuates Alzheimerdisease-like pathology in the PDAPP mouse. Nature. 1999;400: 173-177.

7 Kanai M, Matsubara E, Isoe K, Urakami K, Nakashima K, Arai $\mathrm{H}$, et al. Longitudinal study of cerebrospinal fluid levels of tau, A beta1-40, and A beta1-42(43) in Alzheimer's disease: a study in Japan. Ann Neurol. 1998;44:17-26.

8 Petersen RC, Smith GE, Waring SC, Ivnik RJ, Tangalos EG, Kokmen E. Mild cognitive impairment: clinical characterization and outcome. Arch Neurol. 1999;56:303-308.

9 Klunk WE, Engler H, Nordberg A, Wang Y, Blomqvist G, Holt DP, et al. Imaging brain amyloid in Alzheimer's disease with Pittsburgh Compound-B. Ann Neurol. 2004;55:306-319.

10 Naj AC, Jun G, Beecham GW, Wang LS, Vardarajan BN, Buros $\mathrm{J}$, et al. Common variants at MS4A4/MS4A6E, CD2AP, CD33 and EPHA1 are associated with late-onset Alzheimer's disease. Nat Genet. 2011;43:436-441.

11 Hollingworth P, Harold D, Sims R, Gerrish A, Lambert JC, Carrasquillo MM, et al. Common variants at ABCA7, MS4A6A/ MS4A4E, EPHA1, CD33 and CD2AP are associated with Alzheimer's disease. Nat Genet. 2011;43:429-435.

12 Bancher C, Braak H, Fischer P, Jellinger KA. Neuropathological staging of Alzheimer lesions and intellectual status in Alzheimer's and Parkinson's disease patients. Neurosci Lett. 1993;162:179182.

13 Snowdon DA. Nun Study. Healthy aging and dementia: findings from the Nun Study. Ann Intern Med. 2003;139(5 Pt 2): $450-454$.

14 Matsui Y, Tanizaki Y, Arima H, Yonemoto K, Doi Y, Ninomiya T, et al. Incidence and survival of dementia in a general population of Japanese elderly: the Hisayama study. J Neurol Neurosurg Psychiatry. 2009;80:366-370.

15 Serrano-Pozo A, William CM, Ferrer I, Uro-Coste E, Delisle MB, Maurage CA, et al. Beneficial effect of human anti-amyloidbeta active immunization on neurite morphology and tau pathology. Brain. 2010;133(Pt 5):1312-1327.

16 Vellas B, Black R, Thal LJ, Fox NC, Daniels M, McLennan G, et al. AN1792 (QS-21)-251 Study Team. Long-term follow-up of patients immunized with AN1792: reduced functional decline in antibody responders. Curr Alzheimer Res. 2009;6:144-151.

17 Himeno E, Ohyagi Y, Ma L, Nakamura N, Miyoshi K, Sakae N, et al. Apomorphine treatment in Alzheimer mice promoting amyloid- $\beta$ degradation. Ann Neurol. 2011;69:248-256.

18 Takamura A, Okamoto Y, Kawarabayashi T, Yokoseki T, Shibata M, Mouri A, et al. Extracellular and intraneuronal HMW-AbetaOs represent a molecular basis of memory loss in Alzheimer's disease model mouse. Mol Neurodegener. 2011;6:20.

19 Kang JE, Lim MM, Bateman RJ, Lee JJ, Smyth LP, Cirrito JR, et al. Amyloid-beta dynamics are regulated by orexin and the sleep-wake cycle. Science. 2009;326:1005-1007.

20 Bateman RJ, Siemers ER, Mawuenyega KG, Wen G, Browning $\mathrm{KR}$, Sigurdson WC, et al. A gamma-secretase inhibitor decreases amyloid-beta production in the central nervous system. Ann Neurol. 2009;66:48-54.

21 Kawarabayashi T, Younkin LH, Saido TC, Shoji M, Ashe KH, Younkin SG. Age-dependent changes in brain, CSF, and plasma amyloid (beta) protein in the Tg2576 transgenic mouse model of Alzheimer's disease. J Neurosci. 2001;21:372-381.

22 Shoji M, Matsubara E, Murakami T, Manabe Y, Abe K, Kanai M, et al. Cerebrospinal fluid tau in dementia disorders: a large scale multicenter study by a Japanese study group. Neurobiol Aging. 2002;23:363-370.

23 Hulstaert F, Blennow K, Ivanoiu A, Schoonderwaldt HC, Riemenschneider M, De Deyn PP, et al. Improved discrimination of AD patients using beta-amyloid(1-42) and tau levels in CSF. Neurology. 1999;52:1555-1562.

24 Knopman DS, DeKosky ST, Cummings JL, Chui H, CoreyBloom J, Relkin N, et al. Practice parameter: diagnosis of dementia (an evidence-based review). Report of the Quality Standards Subcommittee of the American Academy of Neurology. Neurology. 2001;56:1143-1153.

25 Itoh N, Arai H, Urakami K, Ishiguro K, Ohno H, Hampel H, et al. Large-scale, multicenter study of cerebrospinal fluid tau protein phosphorylated at serine 199 for the antemortem diagnosis of Alzheimer's disease. Ann Neurol. 2001;50:150-156.

26 Blennow K, Hampel H. CSF markers for incipient Alzheimer's disease. Lancet Neurol. 2003;2:605-613.

27 Hampel H, Teipel SJ, Fuchsberger T, Andreasen N, Wiltfang J, Otto M, et al. Value of CSF beta-amyloid1-42 and tau as predictors of Alzheimer's disease in patients with mild cognitive impairment. Mol Psychiatry. 2004;9:705-710.

28 Parnetti L, Lanari A, Silvestrelli G, Saggese E, Reboldi P. Diagnosing prodromal Alzheimer's disease: role of CSF biochemical markers. Mech Ageing Dev. 2006;127:129-132.

29 Hansson O, Zetterberg H, Buchhave P, Londos E, Blennow K, Minthon L. Association between CSF biomarkers and incipient Alzheimer's disease in patients with mild cognitive impairment: a follow-up study. Lancet Neurol. 2006;5:228-234.

30 Fagan AM, Roe CM, Xiong C, Mintun MA, Morris JC, Holtzman DM. Cerebrospinal fluid tau/beta-amyloid(42) ratio as a prediction of cognitive decline in nondemented older adults. Arch Neurol. 2007;64:343-349.

31 Shaw LM, Vanderstichele H, Knapik-Czajka M, Clark CM, Aisen PS, Petersen RC, et al. Alzheimer's disease neuroimaging initiative. Cerebrospinal fluid biomarker signature in Alzheimer's disease neuroimaging initiative subjects. Ann Neurol. 2009;65: 403-413.

32 Hardy J. The amyloid hypothesis for Alzheimer's disease: a critical reappraisal. J Neurochem. 2009;110:1129-1134.

33 Hyman BT. Amyloid-dependent and amyloid-independent stages of Alzheimer disease. Arch Neurol. 2011;68:1062-1064. 